\title{
Correction to: Electrical impedance tomography in perioperative medicine: careful respiratory monitoring for tailored interventions
}

\author{
Elena Spinelli ${ }^{1}$, Tommaso Mauri ${ }^{1}$, Alberto Fogagnolo ${ }^{2}$, Gaetano Scaramuzzo ${ }^{2}$, Annalisa Rundo ${ }^{3}$, \\ Domenico Luca Grieco ${ }^{4}$, Giacomo Grasselli', Carlo Alberto Volta ${ }^{2}$ and Savino Spadaro ${ }^{2 *}$
}

\section{Correction to: BMC Anesthesiol \\ https://doi.org/10.1186/s12871-019-0814-7}

Following publication of the original article [1], the authors reported that one of the co-authors has a mistake in the author name; the middle name and surname are switched. This is the correct information:

Surname: Grieco

First name: Domenico Luca

The original article [1] has been updated

\section{Author details}

${ }^{1}$ Dipartimento di Anestesia, Rianimazione ed Emergenza-Urgenza, Fondazione IRCCS Ca' Granda Ospedale Maggiore Policlinico, Università degli studi di Milano, Milan, Italy. ${ }^{2}$ Department Morphology, Surgery and Experimental medicine, Anesthesia and Intensive care section, University of Ferrara, Azienda Ospedaliera- Universitaria Sant'Anna, 8, Aldo Moro, Ferrara, Italy. ${ }^{3}$ UOC Anestesia e Rianimazione, Polo ospedaliero Belcolle ASL, Viterbo, Italy. ${ }^{4}$ Department of Anesthesiology and Intensive Care Medicine, Catholic University of the Sacred Heart, Fondazione "Policlinico Universitario A. Gemelli", Rome, Italy.

Published online: 04 September 2019

\section{Reference}

1. Spinelli, et al. Electrical impedance tomography in perioperative medicine: careful respiratory monitoring for tailored interventions. Lipids Health Dis. 2019;18:161 https://doi.org/10.1186/s12871-019-0814-7.

\footnotetext{
* Correspondence: spdsvn@unife.it

${ }^{2}$ Department Morphology, Surgery and Experimental medicine, Anesthesia and Intensive care section, University of Ferrara, Azienda OspedalieraUniversitaria Sant'Anna, 8, Aldo Moro, Ferrara, Italy

Full list of author information is available at the end of the article
}

(c) The Author(s). 2019 Open Access This article is distributed under the terms of the Creative Commons Attribution 4.0 International License (http://creativecommons.org/licenses/by/4.0/), which permits unrestricted use, distribution, and reproduction in any medium, provided you give appropriate credit to the original author(s) and the source, provide a link to the Creative Commons license, and indicate if changes were made. The Creative Commons Public Domain Dedication waiver (http://creativecommons.org/publicdomain/zero/1.0/) applies to the data made available in this article, unless otherwise stated. 